\title{
P351: Undesirable adverse events of the thoracic surgery department of the institute of cardiology of Abidjan
}

\author{
M Adeoti ${ }^{*}$, O Oyourou ${ }^{2}$ \\ From 2nd International Conference on Prevention and Infection Control (ICPIC 2013) \\ Geneva, Switzerland. 25-28 June 2013
}

\section{Introduction}

In the health care system, at least $10 \%$ of the admissions at the hospital involve adverse events (AE) for inpatients, half of them being regarded as avoidable. These events, which can have serious consequences (death, handicap), have a considerable economic impact.

\section{Objectives}

To analyze adverse events occurring in the thoracic surgery department of the ICA and to describe the causes for each type of adverse event.

\section{Methods}

This is a retrospective study of serious adverse events occurring in the thoracic surgery department of the Institute of Cardiology of Abidjan. The study involved the analysis of patient records from 2006-2007 [ha1] . An interview was also conducted with the head of service.

\section{Results}

Of the 113 hospitalized patients, only 80 patients had complete and available records. Thirty-four adverse events were identified and analyzed following an interview with the heads of thoracic surgery.32 AE occurred during the hospitalization; two of these were unavoidable. $73 \%$ of $\mathrm{AE}$ were serious and the incidence rate of $\mathrm{AE}$ in the thoracic surgery department is of $6.89 \% .19$ patients suffered an AE.[ha1] The AE average per patient during care in thoracic surgery is 1.5. Serious adverse events related to invasive acts are the types most observed (38.24\%) in thoracic surgery. $52.9 \%$ of $\mathrm{AE}$ were preventable and $41.8 \%$ likely preventable. $68 \%$ of identified AE were related to the technical aspects of the care of patients that is to say the task.

\section{Conclusion}

This study showed the existence of several failures related to the organization, the task, the environment, the institution and the team.

The challenge for the ICA is, within the limits of current knowledge and techniques, to ensure maximum safety for patients regarding their clinical risk.

\section{Disclosure of interest}

None declared.

\section{Author details}

${ }^{1}$ University Felix Houphouet Boigny, Côte d'Ivoire. ${ }^{2}$ National Institute of Public Health, Abidjan, Côte d'Ivoire.

Published: 20 June 2013

doi:10.1186/2047-2994-2-S1-P351

Cite this article as: Adeoti and Oyourou: P351: Undesirable adverse events of the thoracic surgery department of the institute of cardiology of Abidjan. Antimicrobial Resistance and Infection Control 2013 2(Suppl 1): P351.

${ }^{1}$ University Felix Houphouet Boigny, Côte d'Ivoire

Full list of author information is available at the end of the article

(c) 2013 Adeoti and Oyourou; licensee BioMed Central Ltd. This is an Open Access article distributed under the terms of the Creative 